\title{
REVIEW
}

\section{The contribution to our understanding of spinal disorders by the great Windmill Street School of Anatomy}

\author{
M-F Weiner and JR Silver \\ Emeritus Consultant at the National Spinal Injuries Centre, Stoke Mandeville Hospital, Buckinghamshire, UK
}

\begin{abstract}
Study design: This is a review article.
Objectives: The aim of this study is to investigate the contribution of the private school of anatomy, the Great Windmill Street School, in our understanding of the physiology, anatomy and pathology of the spine and spinal cord and its role in the treatment of spinal diseases in the eighteenth century. Much has been written about the Hunter brothers and Sir Charles Bell and their contribution to anatomy and medical teaching but the significant role of the Great Windmill Street School of Anatomy in our understanding of the spinal cord and the treatment of spinal disorders had not been previously explored.

Setting: Wendover, UK.

Methods: Review of the literature.

Results: Not applicable.

Conclusion: The Great Windmill Street School of Anatomy was unique and fundamental in our understanding of the spine and the spinal cord and the treatment of spinal diseases. What is remarkable is that this work emanated from a private school and not a hospital or a university and it allowed an outstanding school of surgeons and physicians to carry out their work unfettered.

Spinal Cord (2011) 49, 323-332; doi:10.1038/sc.2010.55; published online 8 June 2010
\end{abstract}

Keywords: spine; William Hunter; John Hunter; diseases of the spine; private anatomy schools

\section{Introduction}

At the beginning of the eighteenth century, London was the largest city in Europe and the capital of a worldwide empire. Despite being a centre for medical practice with excellent hospitals, London had no university until 1828 and medical teaching was fragmented. Only Oxford or Cambridge graduates could practise medicine as physicians in the capital, others had to travel to Scotland, Leiden, Paris, Vienna or Padua to obtain a university qualification and then had to obtain a licence from the Royal College of Physicians of London. Hospitals were founded as charitable institutions to treat the sick; their purpose was never formal medical instruction. Enterprising physicians and surgeons therefore established private medical schools to deliver anatomy lectures. Among those, the Great Windmill Street School of Anatomy, founded in 1767 by William Hunter (1718-83) was unique. $^{1}$ Much has been written about its history, the museum and the school's legacy to medicine. This article explores how the personalities of this school of anatomy influenced the management of spinal disorders and enhanced the knowledge of the function of the spinal cord.

Correspondence: Dr JR Silver, 8 High Street, Wendover, Buckinghamshire HP22 6EA, UK.

E-mail: jrussellsilver@btconnect.com

Received 15 March 2010; accepted 6 April 2010; published online 8 June 2010

\section{Medical education in London}

Medical education in eighteenth century London was unsatisfactory. Formal teaching did not take place in the London hospitals and alternative routes were devised to acquire knowledge and medical experience. Traditionally, medical students were apprenticed to an individual surgeon for a period of 7 years at a cost of 500 pounds (around $£ 32000$ today), walking the wards and seeing patients. Alternatively, they could pay to attend private lectures at the hospitals but those were perfunctory, not publicly advertised, poorly attended and of greater benefit to the lecturer, giving him both status and financial reward. ${ }^{2}$ Some surgeons were indolent and did not attend, unlike Benjamin Collins Brodie (1783-1862) who came twice a day to see his patients. William Blizard (1743-1835), a surgeon at the London Hospital, successfully fought against the governors to set up formal lectures and a medical school at the London Hospital. ${ }^{3}$ John Hunter (1728-1793) wished to found a medical school at St George's Hospital but was opposed. Guy's and St Thomas's had a combined medical school, then were split and fragmented and the Middlesex Hospital did not set up a medical school until 1828. Isaac Minors, anatomy steward to the Masters at the Royal College of Surgeons, proposed a school of anatomy at the Royal College of Surgeons with a professor who would lecture and perform dissections, but this 
Table 1 This table shows the absence of formal medical lectures in the hospitals in 1760 , but by 1825 , lectures took place in both the hospitals and the private medical schools

\begin{tabular}{|c|c|c|c|c|c|c|c|c|}
\hline & \multicolumn{2}{|c|}{$1760^{\mathrm{a}}$} & \multicolumn{2}{|c|}{$1780^{\mathrm{a}}$} & \multicolumn{2}{|c|}{$1814^{a}$} & \multicolumn{2}{|c|}{$1825^{\mathrm{b}}$} \\
\hline & Hospital & Other & Hospital & Other & Hospital & Other & Hospital & Other \\
\hline \multicolumn{9}{|l|}{ Central/Eastern London } \\
\hline City & 0 & 4 & 0 & 5 & 6 & 6 & 7 & 7 \\
\hline Southwark & 0 & 1 & 3 & 1 & 7 & 0 & 14 & 8 \\
\hline Whitechapel & 0 & 0 & 0 & 0 & 4 & 0 & 7 & 0 \\
\hline Central/Eastern subtotal & 0 & $100 \%(5)$ & $33 \%(3)$ & $67 \%(6)$ & $74 \%(17)$ & $26 \%(6)$ & $65 \%(28)$ & $35 \%(15)$ \\
\hline Western London & 0 & $100 \%(5)$ & 0 & $100 \%(6)$ & $5 \%(1)$ & $95 \%(20)$ & $7 \%(3)$ & $93 \%(42)$ \\
\hline Total & 0 & $100 \%(10)$ & $20 \%(3)$ & $80 \%(12)$ & $40 \%(18)$ & $60 \%(26)$ & $35 \%(31)$ & $65 \%(57)$ \\
\hline
\end{tabular}

Table reproduced from Charitable Knowledge by Susan C Lawrence, p.192, by kind permission of Cambridge University Press.

${ }^{a}$ Compiled from newspaper advertisements in London daily papers (autumn season only)

${ }^{\mathrm{b} C o m p i l e d ~ f r o m ~ t h e ~ r e p o r t ~ o n ~ m e d i c a l ~ s c h o o l s ~ a n d ~ l e c t u r e r s ~ i n ~ t h e ~ L a n c e t, ~} 1$ October 1825.

too was rejected. Similarly, Edward Harrison's (1766-1838) suggestion for a school of medicine under the aegis of the Royal College of Physicians gained no support. ${ }^{4}$

\section{Dissection}

When William Cheselden (1688-1752) had tried to perform private dissections, he was called to account by the College of Surgeons in $1715 .^{2}$ Dissections could take place at the Royal College of Physicians, the Royal Society and the Surgeons' Hall, but this attracted little interest. The Royal College of Physicians acknowledged that anatomy teaching was poor, blaming insufficient access to corpses for dissection. By 1740, Barber Surgeons in London were allowed to dissect the bodies of criminals hung for homicide, to establish the cause of death, not for teaching purposes, dissection being regarded as further punishment for the condemned (1752 Act). Autopsies and possibly dissections did take place in the hospitals but these were few and of limited extent. Hospital governors were reluctant to host lectures at their hospitals and even less autopsies, fearing for the reputation of the hospital in a religious and mystical environment. ${ }^{5}$ The dissolution of the United Company of Barbers and Surgeons in 1745 relaxed the laws on dissection, allowing them to take place in venues other than the Surgeon's Hall.

\section{Private schools of anatomy}

By the middle of the eighteenth century, medical education in London, whether in hospitals or at private lectures in the Surgeons' Hall, was still unsatisfactory; lectures and notetaking were perfunctory and anyone could practise if they could show satisfactory evidence of anatomical and surgical education in a cursory one hour oral examination by the College of Surgeons. Although the Colleges of Physicians and Surgeons and the Apothecaries were keen to protect their interests and status, they refused to provide any training and were only concerned with the regulation of the profession. The teaching methods at that time were severely criticized by the students themselves and later by
Table 2 With the advent of medical schools in the hospitals in 1871, came the demise of the private schools of anatomy

\begin{tabular}{ll}
\hline Independent anatomy schools & \\
1826 & 1871 \\
Great Windmill St & \\
Little Windmill St & \\
Webb St & None \\
Dean St & \\
Little Dean St & \\
Chapel St & \\
Howland St & \\
Aldersgate St & \\
Hospital anatomy schools & \\
1826 & 1871 \\
& Charing Cross \\
Guy's & Guy's \\
& King's College \\
London & London \\
& Middlesex \\
St Bartholomew's & St Bartholomew's \\
& St George's \\
St Thomas' & St Mary's \\
& St Thomas' \\
& University College \\
& Westminster \\
\hline
\end{tabular}

Table reproduced from appendix I, Richardson R, Death Dissection and the Destitute, London: 1988, by kind permission of Phoenix Press.

Thomas Wakley (1795-1862), the founder of the Lancet. $^{6}$ This barren educational landscape offered an opportunity for enterprising individuals, often unqualified themselves, to establish private anatomy schools (see Tables 1 and 2). Eager students could become independent of patronage and the heavy fees of apprenticeship, and buy themselves a better and less constraining education. Joshua Brookes (17611833), Sir Charles Bell (1774-1842), Joseph Constantine Carpue (1764-1846), Henry Cline (1750-1827), Algernon Frampton (1776-1842), Edward Grainger (1797-1824), Theodore Horsley, Samuel Lane (1802-1892) and the Hunter brothers all owned private anatomy schools in London. ${ }^{2,5}$ Unlike the 'public lecturer', the 'private lecturer' was a selfproclaimed expert who could offer new and original material and an opportunity for students to perform individual dissection. Courses were advertised in the London Evening 


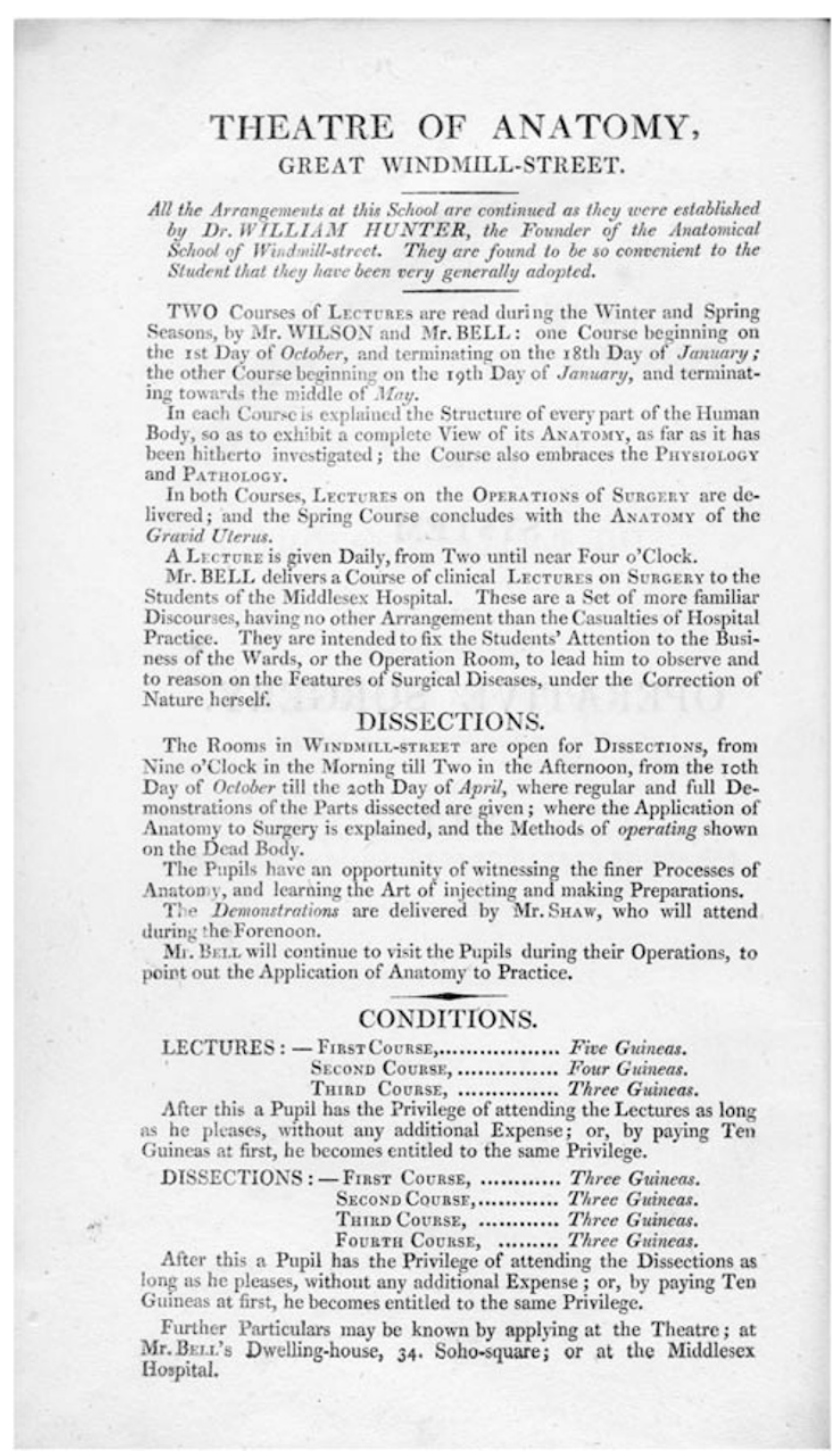

Figure 1 An advertisement for a series of lectures given by Sir Charles Bell and John Wilson at the Windmill School of Anatomy taken from Sir Charles Bell's 'A system of operative surgery founded on the basis of anatomy', volume I, Longman, Hurst, Rees and Orme: London (1814). It is reproduced by kind permission of the Wellcome Library, London. This advertisement shows the unique approach of presenting clinicopathological cases for teaching purposes.

Post and access was given to all who had the means. ${ }^{7}$ Every student was offered a body to dissect; the teaching in the private anatomy schools was innovative, systematic and thorough and far superior to anything available in the hospitals. The popularity of these private lectures confirms how poor the formal medical education was in London at that time, and John Hunter claimed that about 50-60 people attended his brother William's lectures. ${ }^{2}$

The Great Windmill Street School of Anatomy (see Figures 1-5) William Hunter was apprenticed to William Cullen (17101790) in Hamilton, he studied anatomy in Edinburgh and then in both Paris and Leiden to expand his knowledge.

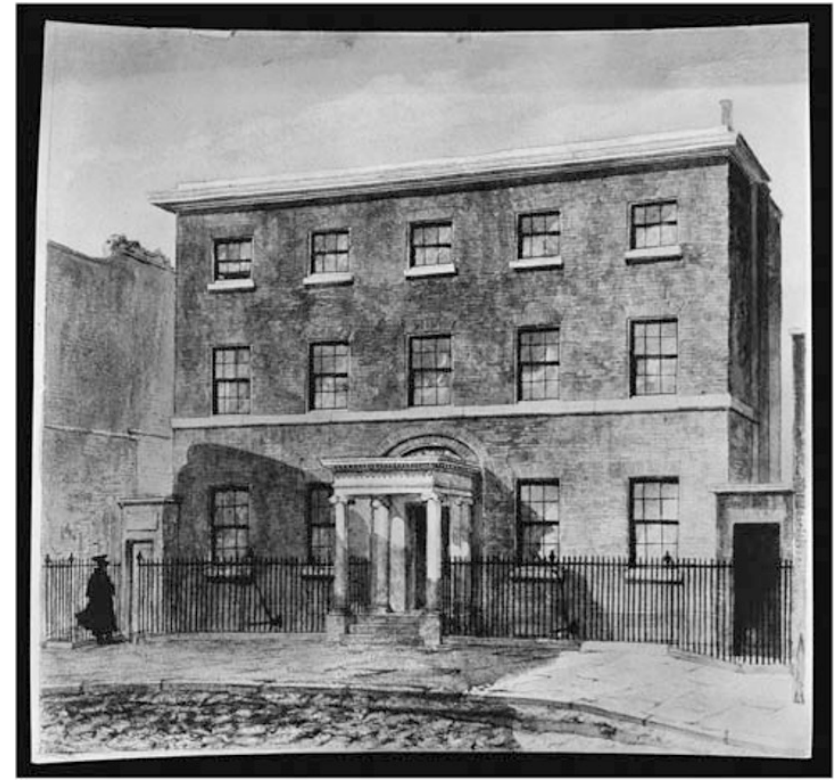

Figure 2 The front view of William Hunter's house and Anatomy School. It is reproduced by kind permission of the Wellcome Library, London.

In London, he was trained under William Smellie (1697-1763), a male midwife (obstetrician), and later became a male midwife to the Middlesex Hospital (a position which held little prestige in the profession). His main interest was dissection. He was a visionary teacher with great oratorical skills, which attracted large audiences. By contrast, his brother John, although charismatic and entertaining, was less gifted at imparting knowledge as he extemporized and philosophized, which confused his students. ${ }^{1}$

William wished to set up a museum in London in 1765 '...for the improvement of anatomy, surgery and physic in London...' and asked the Crown for land (among other sites, he had earmarked Trafalgar Square where the National Gallery stands today). He offered to invest £7000, a considerable sum at the time, but his idea was rejected. In 1745 , he opened a private school of anatomy in Covent Garden. Initially known as the Hunter School of Surgery, it relocated in 1770 and became the Great Windmill Street School of Anatomy; it was both an anatomy school to perform dissections and a museum to house his preparations for study. ${ }^{8}$

Initially William Hunter was in partnership with William Hewson (1739-1774), but they quarrelled over ownership of the specimens Hewson had dissected. After Hewson's departure in 1748, William sent for his 20-year-old brother, John Hunter, whom he trained in anatomy. After 12 years, John Hunter left to join the army and was then apprenticed to Percival Pott (1714-1788) and Cheselden, eventually being appointed on his brother's recommendation to the staff of St George's Hospital as a surgeon. ${ }^{7}$

Most of the teachers and successive proprietors of the school were well-trained Scottish graduates (see Table 3). Although the Hunter brothers themselves did not contribute to our understanding of spinal disorders, many of the people associated with their school of anatomy did and this will be 


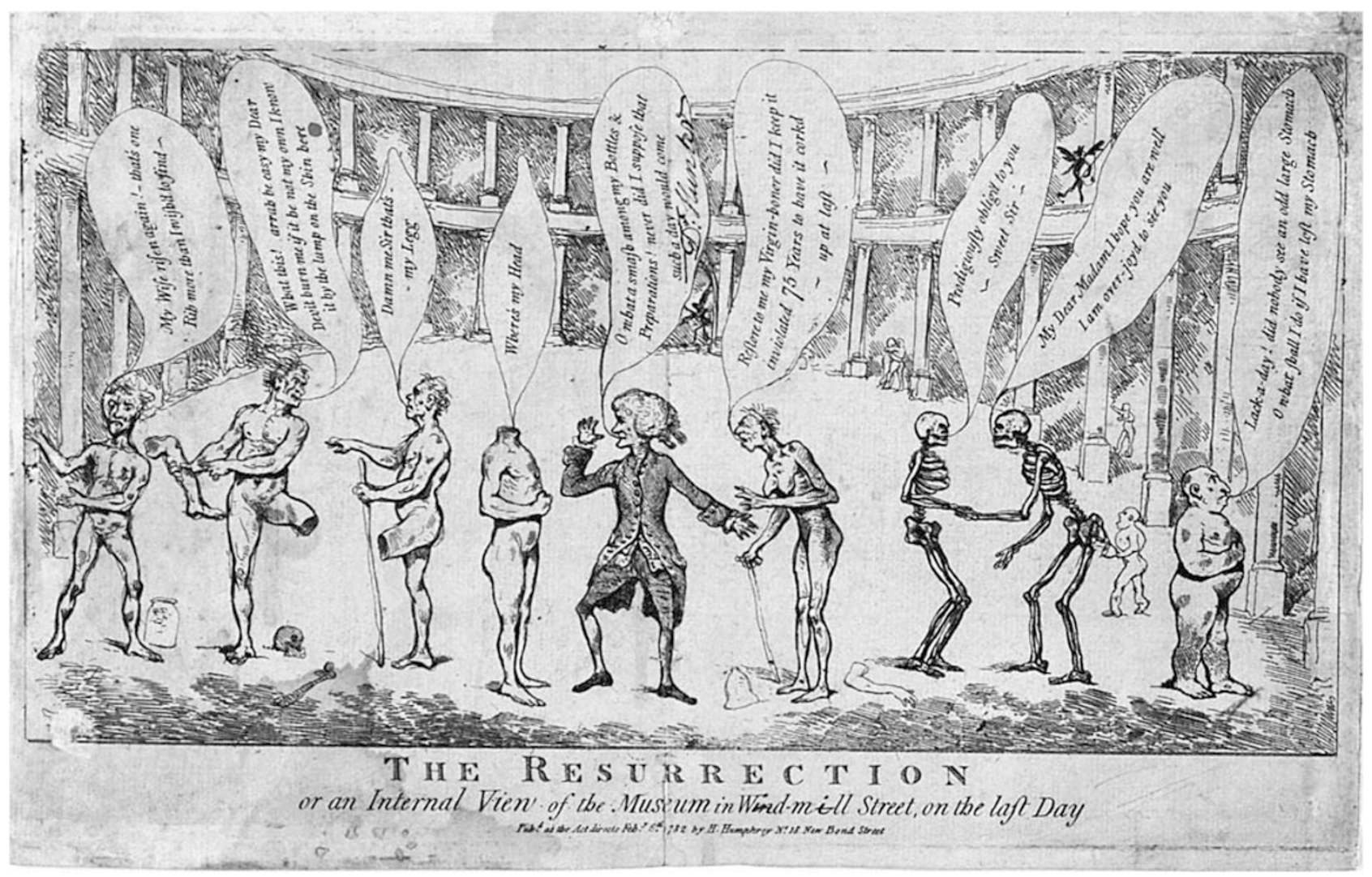

Figure 3 William Hunter in his museum in Windmill Street on the day of resurrection, surrounded by skeletons and bodies, some of which are searching for their missing parts. Engraving, 1782, attributed to Thomas Rolandson. It is reproduced by kind permission of the Wellcome Library, London.

Speech bubbles from left to right:

1. My Wife risen again! That's one rib more than I wish'd to find

2. What's this! arrah be easy my Dear Devil burn me If it be not my own I know it by the lump on the Shin here

3. Damn me Sir, that's my legg.

4. Where's my head.

5. O what a smash among my bottles and preparations! Never did I suppose that such a day would come - John Hunter.

6. Restore to me my Virgin-honor did I keep it inviolated 75 years to have it corked up at last.

7. Prodigiously obliged to you Sweet Sir.

8. My dear Madam I hope you are well I am over-joyd to see you.

9. Lack-a-day did nobody see an odd large stomach O what shall I do if I have lost my stomach.

addressed in detail. The teaching at the Great Windmill Street School of Anatomy attracted both undergraduates and postgraduates, all acknowledged their debt to the school and its teachers. Among them were Edward Jenner (1749-1823), Henry Cline (1750-1833), John Cheyne (1777-1836), Pott, Astley Cooper (1768-1841), John Abernethy (1764-1831) and Everard Home (1756-1832) (John Hunter's brother-inlaw, who became president of the Royal College of Surgeons in 1821-22).

The contribution to our knowledge of the anatomy and diseases of the spine and the spinal cord

The Great Windmill Street School of Anatomy was much more than its name suggests today. In the early nineteenth century, the term 'anatomy' referred to a combination of dissection, physiology, pathology and experimentation, and under the aegis of the Hunter Brothers, this led to numerous scientific advances, such as fundamental discoveries of the lymphatic system and the placental circulation, treatment of hydrocele, experiments on bone growth, treatment of aneurysm, artificial insemination, function of lachrymal ducts, resuscitation techniques and use of placebo studies.

Many fields of medicine benefited from the study taking place in this remarkable establishment, although this article is confined to traumatic injuries of the spine, study of the function of the spinal cord (known today as the speciality of neurology) and deformity of the vertebral column. Until the founding of this school, there had been little interest in the anatomy and physiology of the spinal cord and disorders of the spine. Indeed, detailed analysis of the writings of the Hunter brothers failed to yield any paper on the spinal cord and its function. It was not until the early part of the nineteenth century with the work of Wilson, Brodie and especially Bell that this area was investigated. 


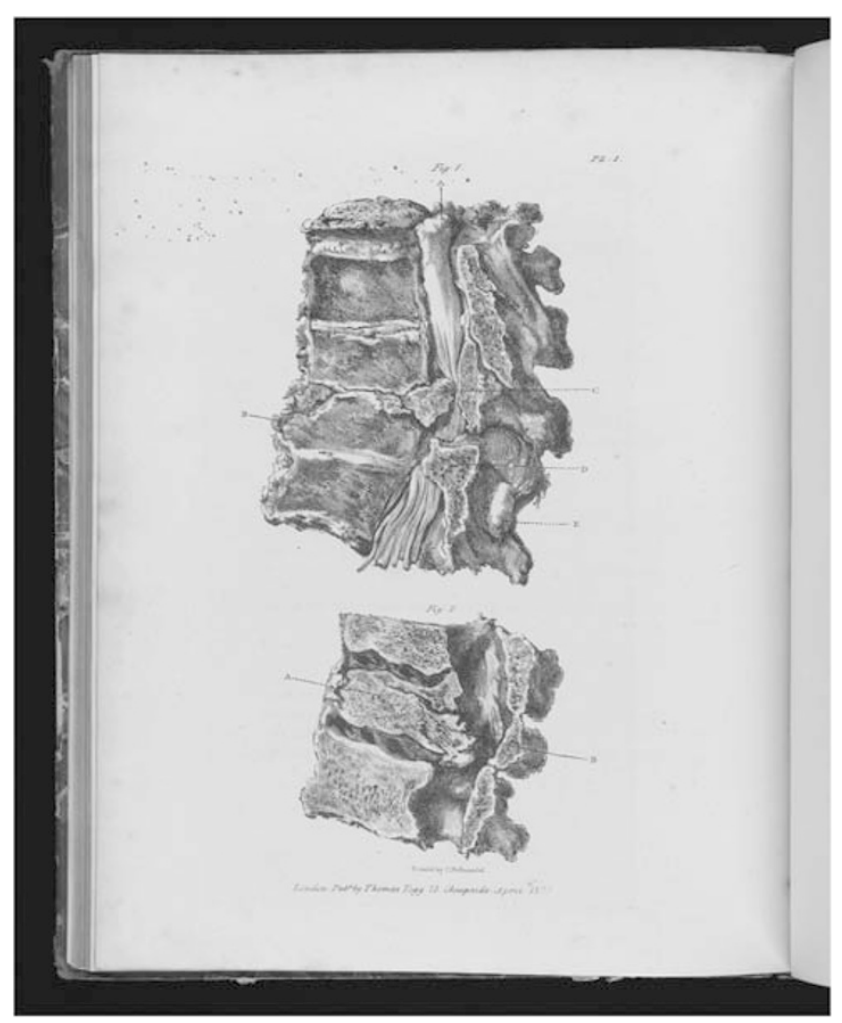

Figure 4 Bell's 1824 illustration of the pathology of spinal cord injury taken from 'Observations on injuries of the spine and of the thigh bone', Plate 1, Thomas Tegg: London (1824). It shows that damage to the spinal cord is anterior and he stresses the futility of trephining posteriorly (Bell 1824). It is reproduced by kind permission of the Wellcome Library, London.

\section{Traumatic injuries of the spinal cord}

In 1824, Cooper, the doyen of British surgeons, gave a detailed description of cases of paralysis following a traumatic injury, with systematic account of injuries at different levels. He described the manifestations of atlantoaxial dislocation on two occasions whereby a child having fallen, initially became paralyzed and then recovered. Subsequently, the child had to hold his head in his hands to support it if he got a knock. A further blow to his head brought about a transient paralysis.

Cooper favourably described how Cline performed a laminectomy on a patient. In addition, Cooper wrote a superb article on Spina Bifida recognizing two approaches: one surgical to try and excise the sac, and the other medical, by compression of the sac with a bandage. He favoured the operation and recognized its association with hydrocephalus and that death was inevitable if the nerves were extruded through the sac. ${ }^{9}$ Despite this account, the major contemporary textbooks by Pott and Abernethy give no description of spinal cord injuries and their treatment. Indeed, Bell commented that:

'It is remarkable that a subject of this magnitude should have so little attracted the attention of the profession. I do not know what books I can direct you to for the authors have treated the subject very superficially and there are only some occasional cases in our books'. ${ }^{10}$
Horse carriage and occupational accidents were frequent in nineteenth century London and many resulted in a traumatic injury to the spinal cord. Bell, Cooper and Brodie devoted much attention to these cases with meticulous studies correlating clinical symptoms with the post-mortem findings and carrying out animal experiments.

Bell like Cooper reported how the instability of the atlantooccipital joint caused sudden death such as after a child was swung by his head, a gesture known in France as 'On faisait voir leur grand-père' or 'to show the child his grandfather'. ${ }^{11}$ Through post mortems, Bell and Cooper showed that the odontoïd peg had dislocated into the spinal canal. ${ }^{11,12}$ A dislocation was more common in the cervical region because of the obliquity of the facet joints, which would permit dislocation more readily, than further down the spine where the facet joints were vertical. Bell gave the first description of a missed fracture of the cervical spine. ${ }^{13}$ Surgeons tried to reduce dislocations by putting patients over a barrel, but such observations were obscured by controversy over the value of laminectomy. Compound fractures of the spine were inevitably fatal due to sepsis. Brodie emphasized the common features of an injury to the cord at different levels to elucidate how it would affect the whole body. He performed a post mortem in the first few days after concussion of the spinal cord and found nothing abnormal, but predicted it would soften later. He described it as an irritation and distinguished it from an inflammation because there was no pus present. Patients immediately acquired pressure sores. He remarked on the diminished movement of the rib cage. Patients with acute cervical lesions might have anaesthesia of the skin but could feel deep pressure when this was applied to the abdomen, thus recognizing the different innervations of the somatic dermatomes as opposed to the innervations of the deep viscera by the autonomic nervous system. In patients with a traumatic transection of the cord, deranged temperature regulation led to hyperpyrexia, slow pulse and anuria. Brodie described the small amount of urine being secreted as acidic, and, subsequently, it became alkaline with a thick coagulant and blood being present, due to renal involvement. He speculated as to whether the changes of the bladder were a primary or secondary effect of the spinal injury. At post mortem, the kidneys were bathed in pus because of ascending infection of the bladder. Brodie recommended conservative treatment with intermittent catheterization but not bloodletting. His observations were thought provoking, farsighted and stimulating, made 100 years before Gordon Holmes' identical findings during the First World War. To this day, these phenomena are ill-understood, have not been fully elucidated and are the subject of speculation and continuing research. ${ }^{14}$

Bell described a fracture of the spine with cord involvement and attributed the retention of urine to the weakened abdominal muscles no longer able to express the urine. Like Brodie, he recognized the significance of retained urine when it became infected giving rise to inflammation that ascended to the kidneys causing renal failure. He recommended drainage of the bladder by intermittent catheteriza- 


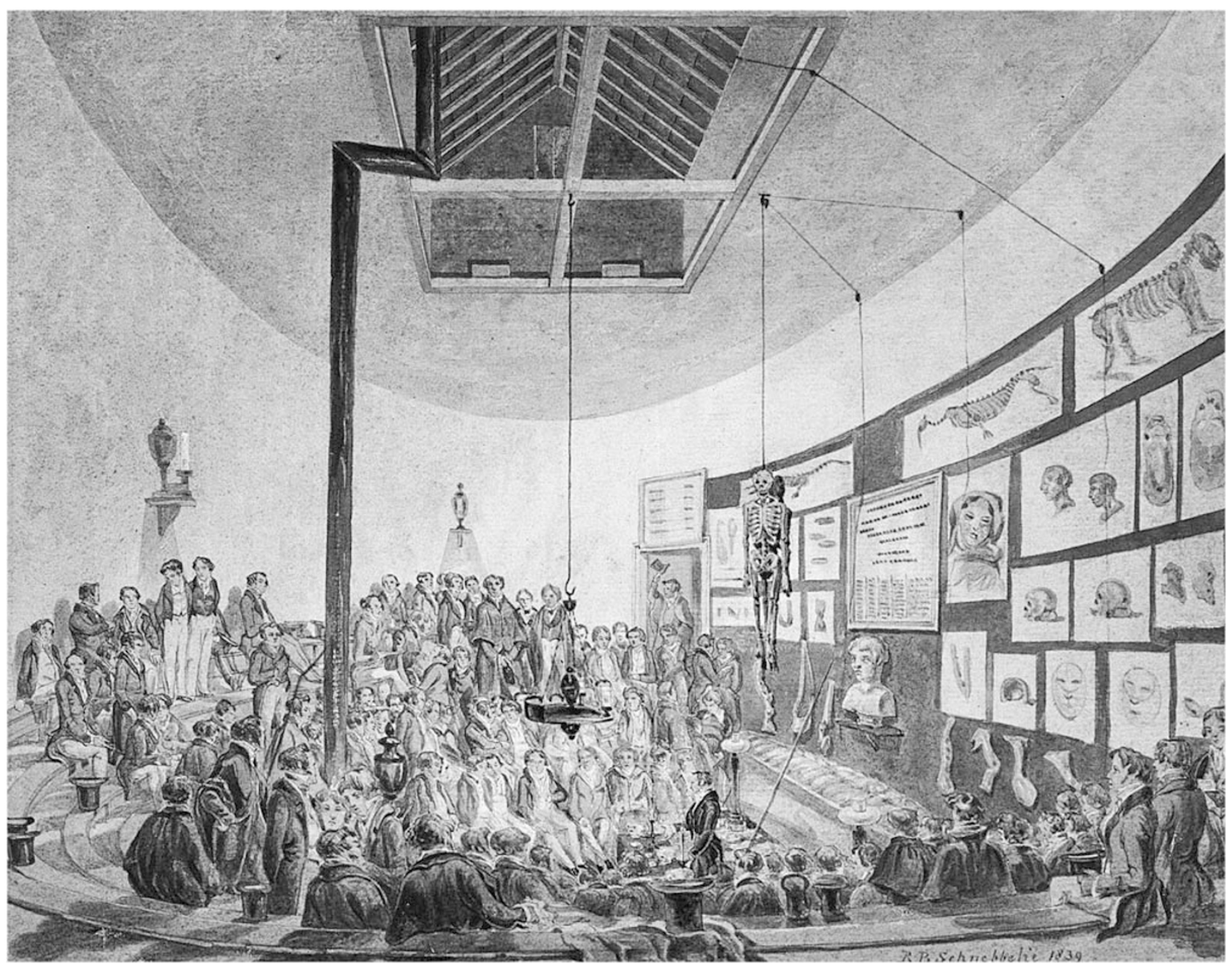

Figure 5 A lecture at the Hunterian Anatomy School, Great Windmill Street, London. Watercolour by Robert Blemmel Schnebbelie (1830). It is reproduced by kind permission of the Wellcome Library, London. This shows a crowded lecture at the Windmill Theatre with a mixed audience of students standing in the background and either surgeons or men about town wanting to be educated in the foreground.

tion and suggested that the surgeon should carry a catheter with him (traditionally in his hat), but warned that the catheter must be introduced carefully as the patient could not feel it being passed and trauma to the urethra could give rise to severe infection, and unfortunately, this complication from catheterization still occurs today. ${ }^{15}$ Bell also recognized the fundamental physiopathology of pressure sores or 'sloughs' due to pressure on the tissues because of the loss of sensation and aggravated by incontinence of bladder and bowel. ${ }^{15}$ Although Bell believed that pressure sores could be prevented by using a specialized bed, performing regular intermittent catheterization of the bladder and controlling the bowels, these principles were not adhered to in a sufficiently systematic manner and most patients eventually succumbed to infection. ${ }^{10}$ Unfortunately, when a patient tried to turn himself, he was forbidden to do so. ${ }^{11}$

\section{Laminectomy}

Cooper advocated immediate surgery in the form of a laminectomy (operation on the vertebra to relieve pressure on the spinal cord) used the analogy that in an injury to the skull, the pressure could be relieved by trepanning. Cline was the first to perform this operation, although it was unsuccessful. Although Cooper was not a blind advocate of laminectomy, he supported Cline in a laudable attempt in a hopeless case. ${ }^{12}$ Cooper's advocacy of laminectomy and his denigration of his opponents as 'blockheads' led to a famous intemperate and public controversy with Bell who vehemently opposed it, believing that cord damage occurred at the time of injury and not through continuing pressure making laminectomy both ineffectual and dangerous. Bell believed that manipulating the patients prone to perform the operation could worsen the situation by moving an unstable fracture. He showed that the fractured vertebra was anterior to the cord so that accessing the damaged area by the posterior approach was difficult and dangerous. He felt that the analogy to trepanning of the skull was illfounded. ${ }^{16}$ Two further laminectomies were performed by Tyrell, a student and nephew of Cooper, and Bells' criticism of the absence of postoperative outcome was an early attempt at audit. Brodie endorsed Bell's views, which have 
Table 3 All the proprietors of the Great Windmill School from William Hunter to Sir Charles Bell were Scottish

The School that William Hunter started in 1746 moved to Great Windmill Street in 1770, and until his death in 1783 was still widely known as the Hunter School. Over its 84 years of existence, the successive proprietors were:

$1746-48$

$1748-60$

$1760-70$

$1771-83$

William Hunter

William and John Hunter

William Hunter and William Hewson

Willliam Hunter and William Cumberland Cruikshank.

1781 Matthew Baillie Joined them.

1783-99 Matthew Baillie and William Cruikshank

1799-1800 William Cruikshank and James Wilson

1800-12 James Wilson assisted by Benjamin Brodie

1812-21 Charles Bell and James Wilson

1821-26 Charles Bell assisted by John Shaw

1827-30 Herbert Mayo and Caesar Hawkins assisted by George Gisborne Babington

John Sheldon also taught at the Hunter School for a short time about 1775-77.

Appendix V, page 186. Extracted from Sir Charles Bell His life and times by Sir Gordon Gordon-Taylor and EW Walls, reproduced by kind permission from E \& S Livingstone Ltd.

Also associated with the Windmill School of Anatomy were Edward Jenner, Henry Cline, Percival Pott, Astley Cooper, John Abernathy and Everard Home.

largely held sway until the present day in the United Kingdom. ${ }^{13}$

\section{Lateral curvature of the spine}

In the early nineteenth century, lateral curvature of the spine generated much interest. This poorly understood condition was attributed to physically demanding occupations such as those of coopers and draymen or faulty posture as with dressmakers and cobblers. Spinal deformity could occur without widespread caries of the spinal column, as unlike Potts' disease, the bone was not tender and there was no discharge and no shortening of life. John Shaw (17921827), ${ }^{17}$ James Wilson (1765-1821), ${ }^{18}$ Bell $^{10}$ and Brodie all described spinal deformity. ${ }^{19}$ Bell lectured on lateral curvature at the Middlesex Hospital and at the Great Windmill Street School of Anatomy, postulating that the spine, vertebrae and ligaments all worked together as a functional whole so that one could not attribute deformity to a single entity. In the early part of the nineteenth century, treatment consisted of manipulation of the spine and mechanical correction with traction and corsets. Bell thought this was dangerous, he favoured a conservative approach and disapproved of 'distortion of the spine by mere mechanics' ${ }^{10}$ Bell referred to Le Vacher's apparatus but insisted that this should not be used for stretching.

'Le Vacher's apparatus is the best. But I may remark upon this subject, that our object should be to support, not to stretch the spine.' If we find that by an apparatus we can elevate the vertebrae which have sunk, yet this should not be done, for the final cure is to be obtained by the anchylosis of the vertebrae; if they have been once destroyed, and have sunk, to separate them is to prevent the natural process of cure. $^{, 15}$
Trained by Bell, his brother-in-law Shaw succeeded Pott as the doyen of spinal practitioners. Bell and Shaw were steeped in Hunter's methods of anatomy, pathology and experimentation to delineate disease. Shaw, the acknowledged expert, treated his patients by mobilization and graduated traction and this became the accepted methodology. He attributed scoliosis to muscle weakness and recommended controlled exercise, friction and massage, to avoid secondary degeneration of the vertebrae such as osteoporosis. Shaw warned against lay practitioners who failed to distinguish between lateral curvature and carious disease of the spine. He also condemned Harrisons' endeavours at reducing a dislocated vertebra. Both Shaw and Bell postulated that manipulation was useless as the spine was fused, and if sufficient force was used to affect correction by fracturing the spine, this could destabilize the spine and damage the cord on movement. ${ }^{17,10}$

Wilson, a Fellow of the Royal Society and professor of anatomy was also a lecturer at the Great Windmill Street School of Anatomy. In Pott's disease, he distinguished between acute collapse of the vertebra causing paraplegia and the gradual collapse, which the spinal cord could accommodate. Softening of the bones due to rickets caused the spine to move sideways, whereas scrofula pushed the spine forward and backward. He put weights on the patient's head and sat them up but he opposed the use of stays. ${ }^{18}$

The anatomy of the nerves (later known as 'neurology') Study of the nervous system lagged behind other medical sciences in the eighteenth and nineteenth century. The function of the anterior and posterior roots of the spinal cord was unknown and it was thought that motor and sensory functions were independent. The brain was regarded as the nerve centre of movement and sensation and the spinal cord, the 'chief nerve of the body', was a conductor of sensation and movement between the brain and the extremities. The posterior columns of the spinal cord were considered to be connected with the posterior roots, as were the anterior roots to the anterior column, with no other known relationship. ${ }^{20}$ While understanding the gross neuroanatomy of the spinal cord and the brain, scientists did not have the adequate means to study the microscopic structure of the spinal cord. They could not begin to understand the function of the spinal cord, as they had no knowledge of the function of the anterior nerve roots, nor of reflex action on which Sherrington's fundamental study on the integrated action of the nervous system was based. Although the importance of the nervous system was acknowledged, very little had been written on diseases of the nerves; there were no textbooks of neurology, only individual papers. The Great Windmill Street School of Anatomy was fundamental in the study of disorders of the nerves and neuropathology with major contributions from Bell, Matthew Baillie (1761-1823), George Mayo (1807-1894) and Shaw.

Bell analysed the gross structure of the spinal cord macroscopically and never used a microscope to delineate the tracts. He believed that there was a tract starting from the cerebrum travelling down through the crus and throughout 
the anterior portion of the spinal cord giving rise to anterior nerve roots, which were responsible for motor action from the brain stem to the cauda equina. The posterior part of the cord linked up to the cerebellum and he thought it was responsible for transmitting sensation, but Bell was not aware of the existence of the crossed spinal thalamic tract, later delineated by Charles-Edouard Brown-Séquard (18171894). Bell also thought that there was a third tract responsible for the respiratory muscles.

Bell considered animal experiments cruel, but reluctantly carried out a remarkable series of trans-sections of the cord on rabbits and cats at different levels, stimulating nerve roots and limbs separated from the body. He used galvanism on cadavers, to stimulate the nerves. ${ }^{21}$ He encouraged Shaw's detailed animal experiments on sensation and motor power. Bell speculated that the spinal cord could have independent nerve centres independent of the medulla, noting that an anencephalic child could still breathe. Stimulation of the anterior nerve roots and the anterior part of the cord with forceps or the tip of scissors caused spasm of the muscles, so that the anterior nerve roots were therefore responsible for movement. Stimulation of the posterior nerve roots did not cause movement. He understood the role of proprioception in that a patient could be aware of a painful stimulus to his legs but unaware of the position of the limb in space. Bell recognized the dissociation between deep sensation to the viscera and anaesthesia of the skin. He was fascinated by the phenomena of phantom limbs and described operating on the nerves of an amputation stump to eradicate this sensation. ${ }^{22}$ These profound observations and insights could not be substantiated because of the limited experimental techniques at that time. Bell's discoveries were overshadowed by his controversy with François Magendie (1783-1855) in which Bell unjustly claimed priority for the discovery of the functions of the anterior and posterior nerve roots. ${ }^{8}$ Mayo who was a student of Bell and subsequently became professor of anatomy at King's College had a similar disagreement with Bell. Mayo carried out beautiful anatomical work in which he correctly delineated the role of the facial and trigeminal nerves in the innervation of the face. Bell impudently claimed priority over this and never acknowledged Mayo's work. ${ }^{8}$ Bell, Shaw and Mayo were all surgeons. Baillie, a protégé of Bell and the only physician in London to carry out post mortems, greatly benefited from his proprietorship of the Great Windmill Street School of Anatomy, in particular, the large number of corpses enabled him to carry out post mortem studies, and as a result, he was the first to correlate pathological descriptions with the organ involved. In his textbook, The Morbid Anatomy of Some of the Most Important Parts of the Human Body (1793), he had a section on pathology of the brain but not on the spinal cord. ${ }^{2}$

\section{Discussion}

In the eighteenth century, London was thriving and a career in medicine could provide an ambitious member of the middle class with a sizable income and the means for social advancement. The Napoleonic Wars had claimed many lives resulting in a dearth of doctors. In consequence, the number of trainee doctors went up from 47 in 1780 to 348 in 1815 , most of them graduating from Oxford, Cambridge, Edinburgh and foreign universities. ${ }^{2}$ Not only was there no medical instruction in London and no university, but there was also ferocious opposition to the founding of medical schools, particularly from the governors of Guy's, the Middlesex and St George's Hospital who considered it a threat to their supremacy. The rise and influence of private medical schools in London and Edinburgh has been extensively analysed by Poynter, Porter and Bynum, Peachey, Lawrence and Richardson, and it suffices to say that among the many private schools of anatomy which opened to fulfil the demand for medical teaching in eighteenth century London, The Great Windmill Street School of Anatomy left an outstanding legacy. It was not 'primus inter pares', but it was unique. It offered a totally different approach to teaching and research. In hospitals, corpses belonged to the surgeons, who performed most of the post mortems, with the exception of Baillie, the only physician to do autopsies. The Hunter brothers rejected long-accepted anatomical principles based on Galen and insisted on discovery by post mortem demonstration and experimentation.

'Were I to guess at the most probable future improvements in physic, I should say that they would arise from a more general and more accurate examination of diseases after death. And were I to place a man of proper talents on the most direct road for becoming truly great in his profession, I would choose a good, practical anatomist, and put him into a large hospital to attend the sick, and dissect the dead.' William Hunter. $^{2}$

They also rejected the traditional style of teaching with a lecturer demonstrating the anatomical parts and instead lectured 'In the manner of Paris', whereby each student was offered a body to dissect and under supervision, was encouraged to 'see with his own eyes and 'touch with his own hands'. This school offered a lucrative and prestigious teaching opportunity and both Brodie and John Hunter gave up their house surgeons' positions at St George's Hospital in order to teach at this school of anatomy. Although no patients were being treated there, it was a research and teaching establishment and the clinical description of disease had to rely on hospital patients, such as Brodie, who described his traumatic cases at St George's hospital. Bell insisted on accurate note-taking as taught in Edinburgh and started the tradition at the Middlesex hospital (see Figure 1) whereby interesting cases from the Middlesex Hospital were discussed three times a week at a clinicopathological conference at the Great Windmill Street School of Anatomy. The school thus became a powerhouse of ideas serving as a college where postgraduates came together and discussed scientific matters. Bell's doctrine was for: 'The intelligent student to make notes without telling him why'. ${ }^{21}$ This approach was later incorporated in the Guy's hospital tradition of the clinical ward whereby the most interesting 
cases were congregated in one ward for observation, recording and teaching. ${ }^{23}$ Accurate note-taking in the eighteenth century has provided us with a unique insight into clinical findings making historical research both accurate and comprehensive. $^{24}$ The Hunter brothers delivered lectures, performed post mortems, carried out research, performed animal experiments and practised comparative and functional anatomy. They produced many beautiful preparations, which were housed in a museum, and which other doctors, Baillie, Cheyne and Shaw among them, used as references to produce illustrations or lecture. ${ }^{25,20,17}$ Porter and Bynum remarked that private schools of anatomy 'provided opportunities to learn and do further research using their museums' ${ }^{25}$ This was certainly true with the Great Windmill Street School of Anatomy, which provided Bell with an inspiring environment for his study on nerves. In his letters, he describes carrying out dissections before lecturing, doing drawings and carrying out experiments on the nerves. ${ }^{26,27}$ Many of the students who honed their anatomy skills with the Hunter brothers became famous in their own right in the United Kingdom, Abernethy, Cline, Cooper, Home and Jenner and abroad, where John Shippen was an associate founder of the first medical school in Philadelphia. A new hierarchy defined by knowledge, writings, position and social and scientific interactions was emerging and doctors such as Bell, Brodie, The Hunters, Wilson and Shaw shared common credentials. They were Fellows of the Royal Colleges, members of the Royal Society, held voluntary hospital appointments, published their scientific findings and lectured, many giving the prestigious Croonian Lecture and receiving prizes. Most had studied in Paris, Vienna or Leiden. The majority were Scottish graduates who were related to each other, who belonged to 'cliques' or Scientific Societies such as the Simmon Society, where Hunter, Home, Brodie, Wilson and Baillie would convene regularly to debate and discuss the latest medical or scientific developments. ${ }^{2}$ Bell, Brodie and Cooper were all appointed to the committee to reform the Royal College of Surgeons, demonstrating their status as the brightest and most influential figures of their time. $^{28}$ All these positions gave them status, notoriety, influence and wealth. They were at the forefront of medicine at a time when Georgian Britain was health obsessed.

Inevitably many of these influential and opinionated people quarrelled with each other, namely, Bell and Cooper, Mayo and Bell, Bell and Magendie, William Hunter and Hewson, William Hunter and Pott, William Hunter and Monro and eventually, the Hunter brothers themselves. These quarrels were mostly but not exclusively about priority of discovery and were a feature of that period in the words of William Hunter:

'It is remarkable that there is scarce a considerable character in anatomy that is not connected with some warm controversy. Anatomists have ever been engaged in contention. And indeed, if a man has not such a degree of enthusiasm, and love of the art, as will make him impatient of unreasonable opposition and of encroachments upon his discoveries and his reputation, he will hardly become considerable in anatomy, or in any other branch of natural knowledge. ${ }^{1}$
Sadly, although many advances were made at the Great Windmill Street School of Anatomy with regard to the anatomy of the spine and the spinal cord as the large number of bodies enabled them to perform post mortems and furthered research, these had little impact on the treatment of traumatic injuries. Bell, Brodie and Cooper gave excellent descriptions of the manifestations of spinal cord injuries long before Gordon Holmes. It was only when spinal injury centres were set up in the middle of the nineteenth century by Wilhelm Wagner (1848-1900), and throughout the twentieth century by Henry Head (1861-1940), George Riddoch (1888-1947), Donald Munro (1889-1973) and Ludwig Guttmann (1899-1980), and patients were properly cared for, by regular turning and draining of the bladder, that the whole natural history of spinal cord paralysis could be delineated. ${ }^{13}$ The one lasting contribution was Bell's opposition to laminectomy, which was widely recognized and is still the accepted management in the UK to this day. In contrast, Pott's description of the pathogenesis of scrofulous disease of the spine was fundamental to our understanding of caries and all (with the exception of Charles Bell and Edward Harrison) acknowledged the primacy of his discovery. Pott recognized that drainage of the abscess of the spine by means of fistulae or setons was necessary for its cure. His work has stood the test of time. Although today anti-tuberculous drugs are the treatment of choice, there is still debate about the necessity or advantages of draining an abscess. Bell and Shaw's contribution to the treatment of spinal deformity was acknowledged at the time and Shaw's work was quoted in France by Levacher. ${ }^{29}$ Although French medicine led the field in Europe, French surgeons came to study under John Shaw. John Shaw was conservative in his treatment, and although the French had been in favour of forceful traction to correct deformity, the practice was eventually condemned by the Paris Academy. Sadly, the dangers of traction had to be rediscovered in the last 30 years. ${ }^{30}$ Bell's contribution to the study of diseases of the nerves was extraordinary. He brought order where there had been disorder. He experimented widely and his studies on stimulating the anterior and posterior nerve roots showed that the posterior nerve roots carried sensation and the anterior nerve roots were responsible for movement. He did similar work on the facial and trigeminal nerves of the face in the ass. Unfortunately, his desire for primacy led him to denigrate the meticulous experiments of Magendie, ignore the work of Mayo and also led to his amending retrospectively his own publications. ${ }^{8}$ Nevertheless, this work long before the opening of The National Hospital for the Paralyzed and the Epileptic was acknowledged contemporaneously by Brown-Séquard who described Bell as a 'genius of physiology' and by Romberg (1795-1873) who described him as '...the Harvey of our century' ${ }^{31,32}$ Clifford Rose and John Pearce, two contemporary historians of neurology, both acknowledge Bell's contribution to our understanding of reflex action. ${ }^{33,34}$ In a few years, he transformed our knowledge of neurology from the primitive Galenic ideas to a framework whereby the reflex action could be delineated, leading to the studies of the integrated action of the nervous system by Sherrington on which modern neurology is based.

Finally, the study of functional disease and hysterical disease of the breast by Cooper and the delineation of hysterical disease of the joints by Brodie was, remarkably, 
carried out not by alienists who looked after lunatic asylums in those days, but by busy practising general surgeons. ${ }^{35,36}$

\section{Conclusion}

Medical practice in London between the middle of the eighteenth century and the early nineteenth century changed irrevocably. Doctors were in great demand but teaching was inadequate and sporadic, and medical students felt disaffected and frustrated as the various medical institutions abdicated their teaching responsibilities. Sensing an opportunity, entrepreneurial surgeons and physicians founded private schools of anatomy, which were to become the bedrock of medical teaching in London for half a century and the precursors of the future hospital-based medical schools. Much of the advancement of medical knowledge in the middle of the eighteenth century did not emanate from the voluntary hospitals but from the work carried out in private schools of anatomy. Without changes to the laws on dissection, it is doubtful that William Hunters' Great Windmill Street School of Anatomy would have had such an impact on the London medical scene. Much of the success of this legendary school was a consequence of the revolutionary teaching and experimental approach of its founders. Numerous fields of medicine benefited from advances made at the Great Windmill Street School of Anatomy and Cooper, Bell, Brodie, Shaw and Wilson, members of a 'new order' of the medical elite, contributed greatly to our knowledge of spinal disorders and the anatomy of the spine. Remarkably and in contrast to the rest of Europe, this study was carried out not in a medical school, a hospital or a university, but in a private school of anatomy.

\section{Conflict of interest}

The authors declare no conflict of interest.

\section{Acknowledgements}

We are grateful to the Wellcome Library for giving us permission to reproduce the illustrations and to Dr Hugh Baron for his constructive suggestions.

\section{References}

1 Peachey GC. A Memoir of William \& John Hunter. William Brendon and son Ltd: Plymouth, 1924, p 59, 115-121.

2 Lawrence SC. Charitable Knowledge-Hospital Pupils and Practitioners in Eighteenth-Century London. Cambridge University Press: Cambridge, 1996, p 158, 82-86, 162, 172, 309, 93, 1, 270.

3 Clark-Kennedy AE. The London A study in the Voluntary Hospital System. Volume One 1740-1840. Pitman Medical Publishing Co. Ltd: London, 1962, p 165.

4 Weiner M-F, Silver JR. Edward Harrison and the treatment of spinal deformities in the nineteenth century. $J$ R Coll Physicians Edinb 2008; 38: 265-271.

5 Richardson R. Death, Dissection and the Destitute. Phoenix Press: London, 1988, pp 38, 61, 76-77, 93, 287.

6 Sprigge SQ. The Life and Times of Thomas Wakley-founder and first editor of the 'Lancet'. Longmans, Green and Co: London, 1897, pp 102-110.
7 Moore W. The Knife Man, Blood, Body-Snatching and the Birth of Modern Surgery. Transworld Publishers: London, 2005, p 76, 305.

8 Gordon-Taylor G, Walls EW. Sir Charles Bell: his life and times. E \& S Livingstone Ltd: Edinburgh and London, 1958, p 49, 52, 113, 129-133.

9 Cooper Sir A. Observations on spina bifida. In: Medico-Chirurgical Transactions London 1811; 2: 323.

10 Bell Sir C. Institutes of Surgery in Two Volumes. Longman, Orme, Brown, Green \& Longmans: London, 1838, Vol 1, p 135, 143, 148, 156.

11 Bell C. Clinical lecture on diseases of the spine. London Medical Gazette 1829, Vol 4, pp 294-298 and 327-333.

12 Cooper Sir A. A Treatise on Dislocations and on Fractures of the Joints. Longman, Hurst, Rees, Orme \& Brown: London, 1823.

13 Silver JR. History of the Treatment of Spinal Injuries. Kluwer Academic/Plenum Publishers: New York, 2003, p 15-16.

14 Brodie B. Medico Chirurgical Transactions, Royal and Medical Chirurgical Society. Longman, Rees, Orme, Brown, Green: London, 1837, pp 118-164.

15 Bell C. A System of Operative Surgery, founded on the Basis of Anatomy Vol II. Longman, Hurst, Rees, and Orme: London, 1809, p 122, 129, 135.

16 Bell Sir C. Observations on Injuries of the Spine and of the Thigh Bone. Thomas Tegg: London, 1824.

17 Shaw J. On the Nature and Treatment of the Distortions to which the Spine and the Bones of the Chest are Subject. Longman, Hurst, Rees, Orme, Brown \& Green: London, 1823, pp 92-97, 152.

18 Wilson JA. Observations on Incurvation of the Spine Arising from Softening of the Bones. Royal College of Surgeons, Burgess and Hill: London, 1821, pp 187-212.

19 Brodie BC. Pathological and Surgical Observations of the Diseases of the Joints. Longman Brown Green \& Longman: London, 1850, pp 281-287 and 342-387.

20 Mc Henry LC. Garrison's History of Neurology. Charles C Thomas: Springfield, Il, USA, 1969, p 183.

21 Bell C. The Nervous System of the Human Body, Papers delivered to the Royal Society on the subject of nerves Longman, Rees, Orme, Brown and Green: London, 1830, p 148. Appendix III and IV and CXXXI.

22 Crumplin M. Men of Steel Surgery in the Napoleonic Wars. Quiller Publishing Ltd: UK, 2007, p 313.

23 Cameron HC. Mr Guy's Hospital 1726-1948. Longmans Green and Co: London, 1954, p 100, 121, 185.

24 Baron JH, Sonnenberg A. History of dyspepsia in Scotland. Scott Med J 2008; 53: 42-44.

25 Bynum WF, Porter R. William Hunter and the Eighteenth Century Medical World. Cambridge University Press: Cambridge, 1985, pp 227-228.

26 Letters of Sir Charles Bell Selected from his Correspondence with his Brother George Joseph Bell. J Murray: London, 1870.

27 Pichot A. The Life and Labours of Sir Charles Bell. Richard Bentley: London, 1860, p 102.

28 Cope Z. The History of the Royal College of Surgeons of England. Anthony Blond Ltd: London, 1959, p 52.

29 Levacher de la Feutrie. Traité du Rakitis. Paris, 1772.

30 Weiner MF, Silver JR. Paralysis as a result of traction for the treatment of scoliosis: a forgotten lesson from history. Spinal Cord 2009; 47: 429-434.

31 Brown-Séquard CE. Course of Lectures on the Physiology and Pathology of the Central Nervous System. Collins Printer: Philadelphia, 1860, p 3.

32 Romberg MH. A Manual of the Nervous Diseases of Man. Sydenham Society: London, 1853, Authors' preface.

33 Clifford Rose F. A Short History of Neurology-The British Contribution 1660-1910. Butterworth Heinemann: Oxford, 1999, pp 122-128.

34 Pearce J. Fragments of Neurological History. Imperial College Press: London, 2003, p 33.

35 Cooper Sir A. Lectures on the Principles and Practice of Surgery as Delivered in the Theatre of St Thomas's Hospital, 4th edn. Henry Renshaw Publisher: London 1835, p 365.

36 Brodie Sir BC. Lecture Illustrative of Certain Local Affections. Londman: London, 1837. 